\title{
Censura literaria en Mallorca: el secuestro de la novela Marius (1967) de Antoni Serra
}

\author{
PILAR ARNAU I SEGARRA
}

\begin{abstract}
Literary Censorship in Mallorca: the Case of the Novel Marius (1967). The repression suffered by the Mallorcan community from the end of July 1936 had great repercussions in the cultural and publishing world of the island. The censor examined all texts that were published, and deleted any content that was not in accordance with the military regime. One of the most curious episodes was the seizure of the novel Marius (1967), by the Mallorcan writer and journalist Antoni Serra.
\end{abstract}

Keywords: literary censorship; Francoism; literature of Mallorca; Antoni Serra

\section{Introducción}

La brutal represión falangista que sufrió gran parte de la sociedad de Mallorca a partir de finales de julio de 1936 tuvo grandes repercusiones en la eliminación de cualquier resquicio republicano o catalanista en dicha isla. El golpe militar triunfó rápidamente, y en casi un año se fusiló al menos a un millar de mallorquines. Sus cadáveres todavía se encuentran en fosas comunes a la espera de ser exhumados ${ }^{1}$.

Respecto a la represión cultural, se prohibieron todos los actos y las publicaciones que recordaban la catalanidad lingüística y cultural de la isla. Se persiguieron con violencia a autores y editores que se atrevieron a publicar libros, textos, o fragmentos de textos, que podían poner en duda los valores impuestos por el régimen militar. Durante años el control de la censura literaria estuvo a cargo de Francisco Soriano Frade, un militar retirado que supervisaba el trabajo de un pequeño equipo de censores, los llamados "lectores". Numerosos editores, como el escritor Camilo José Cela, director entonces de la prestigiosa revista mallorquina Papeles de Son Armadans (1956-1979), debía negociar personal y

1 El 13 de junio de 2016 el Parlament Balears promulgó la "Llei 10/2016, per a la recuperació de persones desaparegudes durant la Guerra Civil i el franquisme”, más conocida como "Llei de Fosses", que permitió e impulsó la apertura legal de las primeras fosas franquistas en Mallorca, lo cual se inició en noviembre del mismo año.

DOI: https://doi.org/10.12697/IL.2017.22.1.8 
directamente con el censor la publicación de cada número de la revista (Arnau i Segarra 2007: 10-11).

Uno de los episodios más peculiares de la represión política cultural en Mallorca fue el secuestro de la novela Marius (Camino hacia la horca), del escritor y periodista Antoni Serra Bauzà (Serra 1967). ${ }^{2}$ El hecho, ocurrido en 1967, se convirtió en el segundo secuestro de un libro en España tras la proclamación de la nueva Ley de Prensa del Ministro Fraga Iribarne y tuvo una gran recepción en los medios de comunicación.

\section{Censura literaria y represión}

La censura literaria que se aplicó durante décadas en Mallorca, y en el resto de las Islas Baleares, no fue un hecho singular, sino que estuvo muy vinculada a la que se sufrió en Cataluña y en el País Valenciano. Además de prohibir cualquier elemento republicano o democrático, se prohibían también las alusiones a la lengua autóctona, el catalán, y, evidentemente, se prohibían también los textos y la manifestaciones públicas, fuesen culturales o no, en esta lengua.

Los estudios sobre la censura franquista acostumbran a destacar que la normativa vigente durante la Guerra Civil y en las décadas de los 40 y 50 fue aplicada de manera rigurosa y severa. Sus efectos empezaron a debilitarse a partir de la segunda mitad de la década de los 50. Sin embargo, la normativa promulgada en 1938, durante la Guerra Civil, reguló la publicación de libros hasta 1966. La censura examinó minuciosamente durante décadas los contenidos de los libros que se querían publicar en catalán, en castellano o en cualquier otra lengua.

Sin embargo, la censura literaria española no solamente consistía en borrar párrafos o páginas enteras, prohibir ediciones o suspender importaciones de libros extranjeros ${ }^{3}$. La censura también cumplía una función muy importante:

2 Debido al secuestro de esta novela, no existen más que dos ejemplares en Mallorca: el que tiene el autor y el que se encuentra en la biblioteca de la Fundación Bartolomé March. En ninguna otra biblioteca pública balear aparece dicha obra su catálogo. Agradecemos a Antoni Serra la amabilidad de habernos prestado su ejemplar clandestino y facilitarnos el acceso a su archivo personal para poder realizar este trabajo.

3 Me refiero a libros publicados en castellano por editoriales hispanoamericanas o por editoriales españolas en el exilio. Es el caso de la famosa editorial Ruedo Ibérico, fundada en 1961 en París por cinco refugiados españoles de la Guerra Civil. Esta editorial alcanzó importancia y prestigio, y logró crear una plataforma de reflexión y discusión que quería ser independiente de toda influencia de partidos. Sus libros tan sólo pudieron circular por España de manera clandestina. Véase Forment 2000. 
su principal objetivo era permitir que otros libros, y otras ideologías afines al régimen, pudieran circular libremente, sin ningún impedimento. (Montejo Gurruchaga 2010: 19)

Así pues, la censura no pretendía tan solo mutilar, secuestrar o inmovilizar centenares de libros, sino también difundir e imponer una ideología concreta. Con este fin, el régimen fascista se abasteció de colaboradores cercanos a su ideología para que trabajasen como "lectores". Es más, los "lectores" eran represores de sus propios compañeros de escritura, ya que, como se ha sabido posteriormente, la mayor parte de los censores no fueron militares o curas, como se solía afirmar, sino escritores y sobre todo aquellos que pretendían serlo. Y dado que la mayor parte de la intelectualidad española durante la dictadura de Franco se encontraba en el exilio, recluida en las cárceles políticas o había sido fusilada, podríamos pensar que formar este ejército de soldados de la pluma represora fue una tarea ardua y dificultosa, pero sin embargo, como afirma Beneyto Pérez (1987: 36) no fue así.

En realidad, quizás pueda sorprender que fuesen tantos los escritores que quisieron ingresar en las nóminas laborales de la censura, pero hay que tener en cuenta unos sólidos motivos que empujaron a tantos españoles a ofrecer sus servicios como "lectores". La precaria situación social, cultural y sobre todo económica de la España de aquellos años nos ayuda a entender esa colaboración intelectual con el régimen franquista:

- En primer lugar, muchos de los “intelectuales” que quisieron permanecer dentro de las fronteras españolas estaban obligados a manifestar públicamente su apoyo incondicional al nuevo régimen militar. No todos los intelectuales habían podido o querido marchar al exilio, y si querían permanecer tranquilos, ellos y sus familias, dentro del país... ¿qué mayor prueba de lealtad al régimen que colaborar en su sistema censor?

- En segundo lugar, hay que tener en cuenta que la situación económica del país, especialmente en los dos primeros decenios de la posguerra, es decir, los años 40 y 50, era miserable. La escasez de trabajo era muy elevada para escritores, maestros, profesores y periodistas, y los que trabajaban recibían sueldos miserables. ${ }^{4}$

En este contexto, la censura ofrecía una remuneración económica que superaba con creces los bajos o inexistentes salarios de muchos españoles en unos tiempos de grave crisis económica, cuando la escasez de alimentos se

4 Es conocido que los maestros estuvieron condenados al pluriempleo durante la larga posguerra: sus exiguos sueldos les obligaban a trabajar fuera de la docencia, sobre todo si tenían familia a su cargo. Un salario de maestro en 1940 era de 3.000 peseta al año. En 1949 era aún de 8.400 pesetas anuales (Nieto 2012: 103). 
controlaba con tarjetas de racionamiento y las privaciones predominaban en una sociedad hambrienta y desprotegida.

Enric Vila, historiador cultural de la censura catalana, añade irónicamente un motivo suplementario: los censores eran los únicos que conocían de primera mano y de manera plausible la literatura que se escribía en el país. Ellos eran los únicos seres privilegiados que podían escribir sus opiniones y leerlas, y ser leídas por otras personas, con toda autenticidad, completamente intactas. Pero la realidad es que no todos los censores destacaban precisamente por tener una capacidad superior de entender los entresijos que a menudo presentaban los textos. Algunos censores eran bastante limitados (Vila 2009: 146).

En Mallorca, la censura estuvo bajo el control de Francisco Soriano Frade. Como Delegado de Información y Turismo controlaba todas las publicaciones que aparecían en la isla. El cargo de censor en Mallorca le fue adjudicado como premio a sus hazañas militares en la Guerra Colonial en Guinea y a su participación en la División Azul, donde fue herido en una batalla contra las tropas soviéticas. Sus conocimientos literarios y culturales en general no eran de gran nivel. Entre las muchas anécdotas relacionadas con la censura mallorquina, está documentado que Camilo José Cela le convenció de que el lingüista Fernando Lázaro Carreter había estado en la División Azul y de que el poeta Blas de Otero no era militante comunista sino un conocido falangista, con lo cual se autorizó la publicación de textos de estos dos autores (Arnau i Segarra 2007: 10-11).

Pero no todo fueron batallas ganadas al censor: en 1953 Soriano Frade abortó el proyecto de la revista Raixa, desautorizando su publicación. A pesar de los intentos de diversas personalidades cercanas al régimen, como el escritor Llorenç Villalonga, Soriano Frade aplicó taxativamente las consignas relativas a la prohibición de las lenguas regionales en las publicaciones periódicas y, por consiguiente, la publicación de la revista Raixa no fue autorizada (Buades 2001: 274).

\section{Marius, historia de un secuestro}

En este contexto de censura literaria y represión lingüística, el periodista mallorquín Antonio Serra (Sóller, Mallorca, 1936) colaboraba en Ultima Hora, el diario más influyente de la isla: sus artículos trataban sobre todo sobre la crítica teatral y cinematográfica. Muy popular en la isla, Serra participaba en actos culturales semiclandestinos y ejercía de conferenciante sobre temas de cultura catalana, siempre desde una perspectiva crítica y contraria al régimen de Franco. A mediados de los años 60, Serra se estrenó como narrador: inició 
su carrera literaria en castellano con la trilogía novelística Camino hacia la horca (1966-1972) que incluía Destinos (1966), Marius (1967) y Radiografía (1972). Las tres obras sufrieron la censura literaria: Destinos solo pudo publicarse con numerosas supresiones; Radiografía, que debía llamarse Los suicidas, tardó varios años en obtener la autorización y solo pudo publicarse tras innumerables forcejeos con la censura. Finalmente se autorizó la publicación de Radiografía, pero con la supresión de treinta y dos páginas y con el cambio de profesión del protagonista de la novela, que pasó de ser militar a abogado.

Marius era la segunda novela de la trilogía. En las ciento sesenta y tres páginas que la componen se narra la historia de Marius Andrade, un profesor de Filosofía huraño, escéptico y muy solitario. El protagonista es un hombre de unos cuarenta años con algunas tendencias paranoicas: "mezcla de "sabio, loco y demonio', según decían las gentes de la ciudad” (Serra 1967: 23). Marius no teme a la muerte, desprecia la humanidad y en repetidas ocasiones se manifiesta como agnóstico, incluso ateo, en una sociedad de arraigadas costumbres tradicionales cristianas. Es profesor de Filosofía, presentaba algunos tics paranoicos que asustaban a sus alumnos: "Algunos padres de familia pretendían que se tomaran medidas oficiales y enérgicas contra el profesor; pedían su destitución, y hasta su reclusión en una casa de salud.” (Serra 1967: 23). El protagonista absoluto de la novela se manifiesta como un ser antisocial, adusto, desagradable e intransigente. A menudo se narran escenas bajo un manto de surrealismo casi cinematográfico, como la descripción de la tétrica procesión:

Las calles quedaron invadidas. Cojos, ciegos, mancos; hombres y mujeres de caras enfermizas, de rostros chupados, de pechos hundidos. Jorobados, tullidos, paralíticos que jamás habían visto la luz del día y que a duras penas empujaban sus propios carretones [...] atropellándose unos a otros, cayendo unos y siendo pisoteados por cuantos les seguían. Quedaba el cuerpo ensangrentado, sucio de polvo y olvidado en medio de la calle.

La gran y monstruosa obra del profesor, había comenzado. (Serra 1967: 104)

Tras diversas gestiones con la censura, la novela Marius fue publicada casi en su totalidad. Y según su propio autor, tras el paso de cincuenta años, esta sería la única novela de la trilogía que le gustaría reescribir en catalán, lengua en la que ha creado toda su obra literaria de ficción a partir de 1970, y publicarla nuevamente (Vicens \& Bennassar 2010: 75).

Pero tras casi un año en venta, Marius fue secuestrada por orden de la Dirección General de Información y Turismo de Baleares, y por lo tanto se retiraron todos los ejemplares no vendidos, tanto los que estaban a la venta en las librerías como los que estaban todavía en los almacenes de la editorial o de 
los distribuidores. Si consultamos el acta de los hechos, podemos leer que en fecha de 8 de mayo de 1967 se personaron las autoridades pertinentes en la editorial Imprenta Politécnica, de Palma, donde se procedió inmediatamente al secuestro.

En realidad ésta fue la segunda novela secuestrada en España tras la aprobación en 1966 de la Ley de Prensa e Imprenta del nuevo Ministro de Información y Turismo, Manuel Fraga Iribarne. Esta ley, conocida popularmente como "Ley Fraga", sustituía la ley que se había decretado nada menos que en 1938, durante la Guerra Civil. La nueva ley de 1966 debilitaba el poder de la censura, ya que, excepto en casos de guerra y en estado de excepción, se aligeraba la censura previa. Ahora ya no era preciso solicitar permiso antes de publicar (libros, periódicos, revistas, etc.) pero se tenía que tener mucho cuidado con lo que se publicaba pues no se podía editar nada que no estuviera de acorde con los principios ideológicos del régimen dictatorial. Según Javier Muñoz, la ley se promulgó porque los propios periodistas y editores estaban cansados de las innumerables trabas que encontraban para llevar a cabo su trabajo y hasta los más afines consideraban que el excesivo control era al final contraproducente, como demostraba la gran caída de los índices de lectura respecto a los tiempos de la República. Además, la censura tan estricta iba en perjuicio de la propia eficacia propagandística del régimen (Muñoz Soro 2008: 115).

Con la nueva ley de censura de 1966 ya no era necesario presentar los textos a la censura antes de publicarlos, sino que simplemente cada autor y cada editor debía meditar sobre la idoneidad de las publicaciones cuando estas estuvieran en el mercado, ya que el régimen imponía restricciones inconcretas. Si no se "respetaban" dichas restricciones, tanto los periódicos como los libros podían ser secuestrados y sus autores condenados a pagar multas, incluso a penas mayores (Muñoz Soro 2008: 117-120).

En el acta mencioanada del día 8 de mayo de 1967 se indica que se procedió al secuestro de los 500 ejemplares que se hallaban en la Imprenta Politécnica, los cuales. se encontraban en pliegos sueltos sin encuadernar. En dicha acta se advertía que la intervención se estimaba necesaria para impedir la difusión, y que para evitar la utilización de los efectos secuestrados, se adoptaban otras medidas: se empaquetaban y lacraban debidamente dichos pliegos que formaban seis paquetes.

Los motivos que se alegaron para secuestrar la novela de Antoni Serra eran que atentaba contra la moral católica, los principios de la Iglesia como institución y además se percibía en ella un ataque contra el orden público y la seguridad general del Estado (Buades 2001: 493). En el archivo personal del escritor hemos encontrado originales y copias de gran parte de la correspondencia que tuvo lugar entre el novelista, su abogado, por una parte, y los juzgados (fiscal y 
jueces) y las autoridades del Ministerio de Información y Turismo (primero las de Mallorca y después también las de Madrid), por otra. Así, en la resolución de 15 de mayo de 1967, el Delegado Provincial del Ministerio en Mallorca considera que el contenido de Marius es ofensivo a la religión católica a través de algunas frases ${ }^{5}$ como: "yo creo en Dios porque es la única esperanza que me mantiene en el deseo de destruirle" (Serra 1967: 24); "antes, mucho antes, yo había condenado la humanidad y a Dios" (Serra 1967: 124); "yo quise ser el asesino de Dios" (Serra 1967: 138); "esta humanidad no me estará agradecida aun cuando quise liberarla de su esclavitud de Dios” (Serra 1967: 152). Además de estas y otras frases similares, las autoridades de la censura imputaron ofensas contra la religión católica y denunciaron "el correlato establecido entre pasajes de la Pasión de Cristo y el proceso criminal de un personaje de la obra, es de notar un ánimo blasfemo e incluso llega al exabrupto en la actitud injuriosa hacia Dios, objetivamente manifiesta en las expresiones vertidas por escrito y en caracteres tipográficos, lo que de por sí supone una insistencia"6.

Estos son solamente algunos de los motivos que se alegaron para secuestrar Marius. Unos días más tarde, en un auto de 19 de mayo, firmado por D. Ignacio Infante Merlo, Juez Especial para los delitos de Prensa e Imprenta de la Jurisdicción de Palma de Mallorca, se arremete contra el secuestro de Marius ya que a partir

de un examen exhaustivo del ejemplar del libro denunciado, remitido a este Juzgado con la denuncia, y en especial de las páginas determinadas a que ésta se refiere, se infiere con carácter rotundo, que en ninguno de los conceptos, expresiones o descripciones vertidas en tal publicación, se infringe alguna de las leyes penales en vigor, tanto en su aspecto definidor de delitos, como en su aspecto menos grave de faltas, ya que el contenido de las páginas pretendidamente inmorales, o comprendida en el arto 431 del Código Penal, no pueden conceptuarse como atentatorio $\mathrm{u}$ ofensivo de la moral o las buenas costumbres, estando todo él dentro de la línea normal de la novela realista moderna [...no se percibe tampoco] intención pornográfica; el contenido de las páginas que se denunció como comprendido en el arto 209 del mismo Código, tampoco hace escarnio de la Religión Católica ni ultraja sus dogmas, ritos o ceremonias, puesto que unas se limitan a expresar opiniones de un personaje literario, tal vez apartado de la religión, que no son necesariamente las del autor, $y$ otras se limitan a describir un banquete que ni por el lugar en que se celebra, ni por las circunstancias de los concurrentes, puede asemejarse a un rito, dogma

Localizamos dichas frases en el texto de la novela y las indicaremos seguidamente cada una con su paginación original.

6 Del acta original citada que se encuentra en el archivo personal del escritor. 
o ceremonia de ninguna religión; y finalmente, menos aun se puede considerar que la opinión de un personaje literario en contra de las revoluciones, signifique la propagación, recomendación o apología de la subversión o la violencia a que se refiere el $\operatorname{art}^{\circ} 2^{\circ}$ letra f) de la Ley de Orden Público, sino evidentemente lo contrario. (Auto 19/05/1967)

El auto del juez Infante Merlo que exoneraba a Serra no fue tomado en consideración, y el caso se trasladó rápidamente a Madrid. Fue entonces cuando el novelista, en calidad de autor-editor, intentó rebatir los argumentos de las acusaciones de atentar contra la moral religiosa en distintas ocasiones, redactando y firmando él mismo las argumentaciones de defensa. Así, en una exposición de alegaciones fechada el 13 de julio de 1967 y dirigida al Ministerio de Información y Turismo, Serra advirtió que las frases citadas "son todas ellas simples citas, las cuales podríamos encontrar examinando obras de hombres tan ilustres como Pio Baroja, Valle-Inclán, etc. O sea, que al no ser opiniones del autor no pueden imputarse los cargos a que se refiere el expediente". Serra continuó su defensa afirmando rotundamente que "ninguna de ellas [las frases mencionadas] va contra la moral católica", y tras unas reflexiones sobre la subjetividad del concepto de moral advertía con vehemencia que

Es inadmisible el cargo imputado por las frases vertidas en el libro, en un
momento, como el presente, en que se ha aprobado una Ley sobre la libertad
religiosa. Cuando cualquier español puede, con plena independencia, sin
coacción alguna, escoger la religión que él entiende satisface sus apetencias
espirituales. (Alegaciones 13/07/1967)

Serra se refería explícitamente a una ley que el régimen de Franco acababa de promulgar tan solo unos días antes. Se trataba de la Ley 44/1967 que regulaba el ejercicio del derecho civil a la libertad religiosa en España. No obstante, de nada le sirvió al novelista este y otros escritos que presentó, solo o junto con su abogado, en los meses siguientes. El novelista en una ocasión incluso se trasladó a Madrid acompañado de su abogado para hablar con el Ministro, pero este no le recibió.

El Ministerio de Información y Turismo redactó con fecha de 15 de noviembre una extensa "Resolución" de seis folios en la que se admitía que el autor había cumplido con todos los términos legales y ofrecía un resumen de los diversos escritos que Serra había remitido, pero insistía en su cuarta página que "MARIUS viola y ofende en su proyección pública a ese principio moral del respeto a las creencias de los demás en cuanto al acatamiento de la Ley de Dios" 
(Resolución 15/11/1967). Es más, el autor de la citada Resolución afirmaba en otro fragmento del texto que de hecho, todo lo acaecido:

constituye tan acusadamente infracción que es irrelevante jurídicamente toda la disquisición que se hace en el pliego de descargos sobre moral, libertad religiosa, etc., que nada dice que pueda desvirtuar lo agresivo que a las convicciones religiosas más elementales resulta el libro, vulnerando directamente el respeto a los principios fundamentales del Movimiento Nacional exigido por la Ley de Prensa e Imprenta y previsto en el art. $2^{\circ}$ de la misma antre [sic] las limitaciones a la libertad de expresión y el derecho a la difusión e informaciones. Siendo DON ANTONIO SERRA BAUZÀ el autor y editor es, pues, el director responsable de la falta administrativa constituida por la expresada violación de la vigente Ley de Prensa e Imprenta. (Ibid.)

Con todo ello, se elevó el expediente "al Excmo. Sr. Ministro para sanción, por estimar que [debido a] los matices subversivos claramente expresados, impone considerar que esta publicación contiene una intención manifiesta de deformar la opinión pública que califica la falta como grave, a tenor de lo dispuesto en el arto. 68 b) de Ley de Prensa e Imprenta."

Evidentemente, el Ministerio quería atajar, tomar una decisión drástica que en este caso era imponer una sanción económica al autor, quien, en su intención de justificar la legalidad de su obra literaria, había cuestionado en diversos escritos la legitimación de la argumentación contraria. Finalmente se resolvió "Imponer la sanción pecuniaria de VEINTICINCO MIL PESETAS de multa a Don ANTONIO SERRA BAUZA en su calidad de autor y editor de la publicación unitaria titulada MARIUS (Camino hacia la horca)” (Resolución 15/11/1967).

Cabe destacar que dicha resolución está fechada el 15 de noviembre de 1967 en Madrid, pero se envió al novelista junto a un escrito de la Delegación Provincial fechado en Palma de Mallorca el 15 de diciembre del mismo año, con lo cual era imposible que Serra pudiera "interponer recurso de alzada ante el Excmo. Sr. Ministro en un plazo de 15 días y previo depósito del importe de la sanción” (ibid.).

Visto lo visto, Serra decidió pagar la multa de 25.000 pesetas, no sin antes enviar una valiente carta al Ministro Manuel Fraga Iribarne (que nunca recibió respuesta) y en la que comunicaba desestimar la posibilidad de recurso y aceptar la multa, pero se atrevía a manifestar irónicamente su desacuerdo con la sanción: 
por cuanto una vez la Dirección General de Información ordenó el secuestro de mi novela, después el Juez para los delitos de Prensa e Imprenta de Palma de Mallorca (o sea, el Ministerio de Justicia) levantó el secuestro indicando que no había lugar al mismo y que los delitos que se me imputaban no eran tales delitos. Pienso que el Ministerio de Justicia sabrá como aplicar "la justicia en nuestro país”. Por otra parte, me ceñí en todo y por todo a la nueva Ley de Prensa e Imprenta.

Considero, por lo tanto, no haber cometido delito alguno y sí el haberme expresado con la libertad a que tiene derecho el escritor en cualquier parte del mundo. Así pues, espero con la serenidad propia del momento y la circunstancia difíciles -gran lección a que nos acostumbraron los escépticos y estoicos - las medidas del cobro de la sanción por Vía Administrativa de Apremio. El escritor, tras haberse convertido su profesión en la más peligrosa y arriesgada de nuestro país, debe -con su voto de pobreza - tener el ánimo dispuesto a lo mejor y a lo peor, pero nunca debe renunciar a sus creencias ni a su libertad - de expresión y de pensamiento. (Carta A. Serra 20/12/1967)

En realidad el secuestro de la novela Marius fue más bien objeto de una venganza. La novela no presenta un ideario político o ideológico que pudiera atacar abiertamente al régimen franquista. Se intuyen las desavenencias más bien mediante la sátira, incluso la burla, que se manifiesta unas veces más sutil, otras más explícita, pero sin mencionar nunca expresamente la autoridad. Las alusiones a Dios pueden ser del desagrado de algún lector creyente, partidario de los preceptos de la religión católica más tradicional, pero, teniendo en cuenta que se ponen en boca de un personaje literario de ficción al que se le atañen problemas de salud mental, se percibe claramente la intención manipuladora y autojustificativa de la autoridad competente.

Estamos, pues, ante un acto político movido por otras causas. Según nuestra opinión, el secuestro de la novela Marius (Camino hacia la horca) fue una venganza política contra su autor. A mediados de los años sesenta Antoni Serra era ya un conocido crítico teatral y periodista cultural de la prensa mallorquina. Participaba regularmente en diversas tertulias, como la que se organizaba en el Bar Mocka, donde se reunían pintores, escultores, periodistas, etc., para analizar la actualidad política, siempre teniendo en cuenta que se hallaban inmersos en una dictadura militar. También asistía a las tertulias literarias de la Cafetería Riskal, que tenían como personaje principal al gran novelista Llorenç Villalonga (Palma 1897-1980). Serra conocía a las principales figuras de la cultura mallorquina del momento, y ejercía su influencia no solamente como crítico sino también como conferenciante, ocupación que le permitía manifestar, no sin cierta ironía, su desacuerdo con el régimen franquista. En poco tiempo adquirió la fama de crítico con el sistema, hasta el punto que en 
todas sus conferencias asistían policías de la secreta y, en numerosas ocasiones, ya le advertían antes de empezar el acto de las consecuencias fatídicas que podía acarrearle el hecho de no atenerse al guión autorizado ${ }^{7}$ (Vicens \& Bennassar 2010: 39). En este contexto, el conferenciante Antoni Serra no pudo finalizar más de una conferencia y acabó en comisaría donde tuvo que dar explicaciones del contenido de sus disertaciones. Políticamente, tuvo contactos clandestinos con antifranquistas mallorquines, los cuales en aquellos años se concentraban principalmente en pequeños círculos comunistas.

Serra pensaba que el teatro podía generar la toma de conciencia política de la sociedad y con ello deteriorar los fundamentos del Franquismo. Compartía dicha convicción con Jaume Adrover (Puigpunyent 1929 - Palma 2015), hombre de teatro donde lo hubiere, con quien Serra aprovechó un ciclo de conferencias que organizaba el Círculo Medina - una entidad de tendencia falangista que dependía de la Sección Femenina- para introducir la participación de intelectuales considerados peligrosos por el Franquismo, como el mismísimo dramaturgo Alfonso Sastre (Madrid, 1926).

Un año antes del secuestro de Marius, es decir, en 1966, Antoni Serra había participado junto con Jaume Adrover y otros intelectuales mallorquines, entre los que destacaba Josep M. Llompart (Palma 1925-1993), y Bienvenido Álvarez Novoa -un joven militante antifranquista-, en la creación de una serie de actos culturales que bajo el título de "Aules de Poesia" tuvieron lugar en la primavera de ese mismo año en Palma. Un año más tarde, en la primavera de 1967, y en un espacio más amplio y con mayor aforo, la Casa Catalana de Palma, tendrían lugar las "Aules de Teatre”. Esta vez participaron más de veinte autores dramáticos, tanto castellanos como catalanes, así como otros autores y personalidades del mundo cultural cuyo denominador común era el de no ser autores adictos al régimen. Personajes de la talla de Pere Calders, Joan Oliver (Pere Quart), Josep Maria Castellet, Caballero Bonald o José Luís Aranguren despertaron la curiosidad de muchos ciudadanos. (Vicens \& Bennassar 2010: 50). La acogida de las "Aules" entre la juventud mallorquina del momento y en general entre la intelectualidad insular fue enorme, hasta el punto de que la policía, más tarde, se quejó de no haberlas prohibido por desconocer su importancia y su difusión. Antoni Serra fue sin duda alguna uno de los mayores promotores de dichas jornadas. A pesar de las dificultades que requerían la obtención de los permisos y las autorizaciones pertinentes para llevarlas a cabo, parecía que todo iba por buen camino. Pero la policía quiso crear un clima de

En aquellos años era habitual que miembros de la Brigada Político-Social, la policía secreta franquista, asistieran a los actos públicos, y que se presentara previamente a censura al menos un guión de la conferencia que se quería impartir. 
incertidumbre realizando, unos días antes de la inauguración de las "Aules", algunos registros en los domicilios de los organizadores y enviando un número más elevado de policías de paisano a los actos. Se prohibieron dos conferencias por ser sus conferenciantes los más conocidos y comprometidos: la del filósofo López Aranguren -que finalmente se pudo realizar, de manera clandestina, en el Hotel Jaume I- y la del poeta Pere Quart. Durante la sesión de clausura que tuvo lugar el 16 de mayo de 1967 -ocho días después del secuestro de la novela Marius-, el poeta catalán Pere Quart debía impartir la conferencia "El teatre de postguerra al Principat". La prohibición fue comunicada a los organizadores unos minutos antes del inicio previsto, con el recinto llena hasta la bandera. Los asistentes abandonaron la sala en silencio, pero, al sumarse Pere Quart al cortejo, los asistentes empezaron a aplaudir y se generó una gran ovación. En este momento diversos militantes antifranquistas aprovecharon para presentarse en público, e incluso una conocida comunista, Francisca Bosch, se ofreció voluntaria para leer en público la conferencia prohibida. (Arnau i Segarra 2011: 49-51). Esta fue la primera vez que en Mallorca un grupo de intelectuales se manifestaba públicamente contra el Franquismo. Y el periodista y novelista Antoni Serra estaba en primera fila. A partir de ese momento, y durante varios años, Serra fue vigilado de manera constante y sistemática por la policía del régimen, se registró a menudo su domicilio, se le detuvo por la calle y pasó alguna noche en comisaría. (Vicens \& Bennassar 2010: 52). Incluso un inspector de policía lo denunció porque, a raíz de la presentación de la película Roma, ciudad abierta en Ibiza, se habían hecho alusiones a los nazis, los fascistas e incluso a la policía española. En sustitución de arresto carcelario, se le impuso al escritor una nueva multa gubernativa (Abellán 1980: 223).

\section{Conclusiones}

En resumidas cuentas, el secuestro de Marius coincidió plenamente con un gran despliegue de actividad represora contra la realización de los actos culturales organizados en la sede de la Casa Catalana de Palma (Abellán 1980: 220), y entre los que destacaron precisamente las "Aules" de 1967. La reacción pública de los delegados del Ministerio de Información y Turismo en Mallorca fue la prohibición por orden gubernativa de la conferencia del poeta Pere Quart, que ya contaba con el permiso oficial por escrito, y la del conocido profesor Aranguren. Pero estos hechos estaban vinculados a otro de anterior, cuya intención había sido disuasoria: el impedimento de la distribución y venta de una obra literaria de uno de los organizadores de las "Aules".

Así, pues, con el secuestro de Marius se quiso asestar un duro golpe a uno de los adalides de las actividades culturales antifranquistas. Promotor de 
numerosos actos culturales mal vistos por el régimen y periodista que adquiría una gran notoriedad a través de las columnas del diario Ultima Hora, Serra era considerado un peligro para la moral y la ideología que defendía el régimen.

José Manuel Abellán considera que con dicho secuestro "el Franquismo podía represaliar de este modo indirecto las 'Aules de Cultura' sin tener que recurrir a una prohibición total de las mismas que hubiera provocado mucho mayor revuelo que el simple secuestro de la novela de uno de los principales animadores" (1980: 221). Efectivamente, se quiso disuadir al novelista, y a todos quienes querían participara en las "Aules" de 1967, mediante el secuestro de Marius, además de realizar registros domiciliarios y aumentar la presencia policial. Ahora bien, no se quiso imponer la prohibición por orden gubernativa de todo el ciclo de conferencias, lo cual hubiera podido tener un efecto negativo para la imagen del régimen. Con ello percibimos que "un secuestro ha sido a veces sólo uno de los medios posibles de represión que el Franquismo tenía a mano para frenar el dinamismo cultural que se manifestaba en la vida social española. (Abellán 1980: 223). Y en la Mallorca de finales de la década de los sesenta, hubo una gran eclosión cultural y política, desarrollada, precisamente a raíz de las "Aules de Teatre" de finales de mayo de 1967.

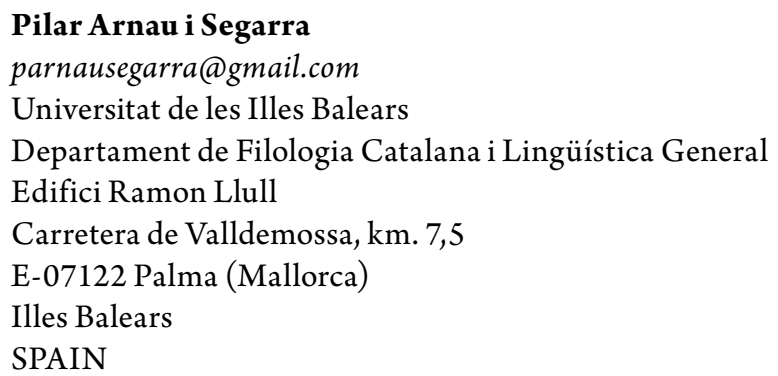

\section{Bibliografía}

Abellán, M. 1980. Censura y creación literaria en España (1939-1976). Barcelona: Ediciones Península (Tema de historia y política contemporánea 9).

Arnau i Segarra, P. 2007. Introducció. - Josep M. Llompart, Articles i traduccions a Papeles de Son Armadans (1956-1961). Barcelona: Publicacions de l'Abadia de Montserrat, 5-29.

Arnau i Segarra, P. 2011. Josep Maria Llompart. Un home polifacètic al servei del país. Palma: Ajuntament de Palma (Biografies de Mallorquins 27).

Beneyto Pérez, J. 1987. La censura literaria en los primeros años del Franquismo. Censura y literaturas peninsulares. Diálogos Hispánicos de Amsterdam, 5. Amsterdam: Rodopi, 27-40. 
ARNAU I SEGARRA

Buades i Juan, J.M. 2001. Intellectuals i producció cultural a Mallorca durant el franquisme (1939-1975). Palma: Edicions Cort.

Forment, A. 2000. José Martínez: la epopeya de Ruedo Ibérico. Barcelona: Anagrama.

Montejo Gurruchaga, L. 2010. Discurso de autora. Género y censura en la narrativa española de posguerra. Madrid: Universidad Nacional de Educación a Distancia.

Muñoz Soro, J. 2008. Vigilar y censurar. La censura editorial tras la Ley de Prensa e Imprenta, 1966-1976. - Ruíz Bautista, E. Tiempo de censura. La represión editorial durante el Franquismo. Gijón: Editorial Trea, 111-141.

Nieto, C. et al. 2010. Don José Nieto, maestro nacional (1915-1965). San Vicente (Alicante): Editorial Club Universitario.

Serra Bauzà, A. 1967. Marius (Camino hacia la horca). Palma: Imprenta Politécnica.

Serra Bauzà, A. 1981. Gràcies, no volem flors. Cròniques de la clandestinitat a Mallorca. Barcelona: La Magrana.

Vicens Escandell, A., Bennassar, S. 2010. Antoni Serra, la ploma i el capell. Pollença: El Gall Editor.

Vila, E. 2009. El nostre heroi Josep Pla. Barcelona: Acontravent.

\section{Documentos citados con sus abreviaturas:}

“Acta” del secuestro policial, 8 de mayo de 1967, tres páginas [Acta 8/05/1967]

"Resolución” del Delegado Provincial de Información y Turismo, 15 de mayo de 1967, 6 páginas [Resolución 15/05/1967]

"Auto", firmado por D. Ignacio Infante Merlo, Juez Especial para los delitos de Prensa e Imprenta de la Jurisdicción de Palma de Mallorca, 19 de mayo de 1967, 4 páginas [Auto 19/05/1967]

"Alegaciones" (copia) de Antonio Serra Bauzà contra los cargos imputados, 13 de julio de 1967, tres páginas [Alegaciones 13/07/1967]

"Resolución" del Ministerio de Información y Turismo, Dirección general de Información, Sección: Asuntos Generales, (Madrid) 15 de noviembre de 1967, seis páginas [Resolución 15/11/1967]

"Informe" de la Delegación Provincial del Ministerio de Información y Turismo (Palma de Mallorca), 15 de diciembre de 1967, cinco páginas [Informe 15/12/1967]

Copia de la carta de Antonio Serra Bauzà al Excmo. Sr. D. Manuel Fraga Iribarne. Ministro de Información y Turismo, de 20 de diciembre de 1967, una página [Carta A. Serra 20/12/1967] 